\title{
Gender Differences in Adolescent Advertising Response: The Role of Involvement and Message Claim
}

\author{
Karlijn Massar ${ }^{1}$, Abraham P. Buunk ${ }^{2,3}$ \\ ${ }^{1}$ Work \& Social Psychology, Maastricht University, Maastricht, The Netherlands \\ ${ }^{2}$ Social \& Organizational Psychology, University of Groningen, Groningen, The Netherlands \\ ${ }^{3}$ Royal Netherlands Academy of Arts and Sciences, Amsterdam, The Netherlands \\ Email: karlijn.massar@maastrichtuniversity.nl
}

Received April 17 ${ }^{\text {th }}, 2013$; revised May $19^{\text {th }}, 2013$; accepted June $18^{\text {th }}, 2013$

\begin{abstract}
Copyright (C) 2013 Karlijn Massar, Abraham P. Buunk. This is an open access article distributed under the Creative Commons Attribution License, which permits unrestricted use, distribution, and reproduction in any medium, provided the original work is properly cited.
\end{abstract}

\begin{abstract}
This study investigates whether gender differences in adolescents' advertising judgments and purchase intentions are due to their level of involvement with the advertised product, and with the claim made in the ad, i.e. whether evaluative versus factual message claims are used. Male $(\mathrm{n}=115)$ and female adolescents $(n=127)$ were randomly assigned to a mixed design. They read either factual or evaluative ads (between-subjects variable) about a product within and about a product outside their area of interests (within-subjects variable). Results show that when an ad contained a description of a high involvement product (i.e. the youth magazine), adolescent females were persuaded most by factual information, whereas when the ad contained a description of a low involvement product (the sports magazine), they were persuaded more by evaluative information. Adolescent males overall indicated a more positive attitude towards a high involvement product, but were equally persuaded by evaluative and factual information. We conclude that gendered advertising responses do exist, and that the level of involvement with the product advertised determines which type of message claim - factual versus evaluative - is most effective for each gender. Discussion focuses on theoretical and practical implications of these results.
\end{abstract}

Keywords: Gender Differences; Advertising Response; Product Involvement; Message Claims

\section{Introduction}

Men and women differ in the things they find interesting and the activities they prefer to engage in. These differences are already evident very early on in life. For example, Alexander, Wilcox, and Woods (2009) report that infants ranging in age from 3 to 8 months show gender differences in visual interest in sex-linked toys. These differences in toy and play preferences remain throughout childhood and adolescence (e.g., Trainor, Delfabbro, Anderson, \& Winefield, 2010), with boys spending more time than girls on activities by themselves and on physical past-times such as skating, bowling and riding scooters. On the other hand, girls tend to spend more time than boys on reading, writing and listening to music. Moreover, boys and girls express more positive competence beliefs for these activities (Eccles, Wigfield, Harold, \& Blumenfeld, 1993). These gender differences in interests persist during adulthood, and seem to be stable across cultures and over time (Lippa, 2010), with women generally more interested in "people" and men more interested in "things".

One would expect that these differences in interests and leisure activities would also translate into consumer behavior. Indeed, men and women have been found to show an interest in, and talk about, different products (Slama \& Williams, 1990). Gender - in addition to age, marital status, income, and education-is one of the variables often used in market segmentation, and gender segmentation has been applied for years in market- ing, especially regarding clothing, cosmetics, and magazines (Kottler \& Keller, 2006; Nysveen, Pedersen, \& Thorbjørnsen, 2005). Thus, an understanding of gender-based processing differences of advertisements is important to marketers, since it enables them to communicate with (i.e., access) these different market segments and to produce effective promotions for each segment. Research suggests that there are gender differences in the information processing of messages and ads (for an overview, see Wolin, 2003), for example, it has been found that women process information more elaborately than men, and that repetitive exposure to ads tends to be more effective for women than single advertising exposure.

Much of the research on gender differences in information processing was stimulated by the development of the Selectivity Hypothesis (Meyers-Levy, 1989), which is based on the assumption that both genders differ in the way they interpret the external world and how they process persuasive information. According to this hypothesis, males' interpretational mode is largely categorical - they adapt to a situation by constructing laws, rules and attitudes. They do not engage in comprehensive processing of all available information, but instead are selective, and tend to use heuristics and simple cues as a basis for their judgment. Females, on the other hand, are thought to form judgments by considering the internal aspects of personal and social situations, and tend to be comprehensive information processors who consider all available product attributes. For example, women are more likely than men to read product la- 
bels (Mueller, 1991). Though capacity restrictions in active memory may prevent women from accomplishing this goal, the selectivity hypothesis states they give equal attention to all available promotion information (Meyers-Levy, 1989; MeyersLevy \& Maheswaran, 1991; Meyers-Levy \& Sternthal, 1991).

Support for the selectivity hypothesis has been reported in a number of studies. For example, a study by Laroche, Saad, Cleveland, and Browne (2000) showed that when shopping for a gift, women's information search process was more systematic and comprehensive than men's. Men on the other hand tended to rely more on heuristic strategies - such as relying on brand names and product price, or directly consulting a sales clerk to quickly obtain what was needed. Further support for the selectivity hypothesis comes from a study by Mitchell and Walsh (2004), which showed that males' consumer decision making style was characterized most by a time-saving orientation, whereas females' decision making style reflected variety-seeking and recreation. Put differently, males did not give their purchases much thought, did not want to spend much time shopping, and preferred the number of products in their consideration set to be limited. Females on the other hand enjoyed the activity of shopping itself, focused on the quality of products, and liked trying out new brands regularly. Thus, to summarize, there seems to be considerable support for the Selectivity Hypothesis' main contention that males make consumer decisions in a heuristic way, whereas women base decisions on all aspects of the available information.

However, there are other factors that may influence information processing and advertising response. Not only do people differ in the amount of information they can and will process, but advertisements themselves can differ in the way products are described, that is, message claims will influence consumer decisions to a large extent. The claims in a message vary in the nature of the language that is used (Holbrook, 1978; Darley \& Smith, 1993), and this in turn has effects on the ad's persuasive quality. Broadly, two types of message claims can be distinguished, termed by Holbrook (1978) as factual and evaluative messages. Factual message claims are defined as "logical, objectively verifiable descriptions of tangible product features" (Holbrook, 1978: p. 547), for example: "This lawn mower has a purchase price of $\$ 78$ and an average life span of 6 years". In contrast, evaluative message claims are "emotional, subjective impressions of intangible aspects of the product" (Holbrook, 1978: p. 547). An example of an evaluative message would be: "This lawn mower has a surprisingly low purchase price and a lengthy life span". In the current paper, we will use these terms to refer to the type of message claims used in promotion information.

Most research on advertising claims has found that in general, factual claims are perceived as more credible than evaluative claims (Holbrook, 1978), and evaluative claims evoke more skepticism in consumers (Tan, 2002), and generate less cognitive resistance (Edell \& Staelin, 1983). However, based on the selectivity hypothesis on gender differences in information processing, men and women are expected to react differently to these different message claims due to their different information processing styles. Specifically, women, being comprehensive processers, are expected to be more likely to attend to both factual and evaluative message claims, whereas men are expected to attend primarily to factual messages, since these provide an opportunity for quick, heuristic processing. A study by Darley and Smith (1995) showed that females showed evidence of being comprehensive processers, responding favorably to both evaluative and factual message claims in terms of ad credibility, argument quality, ad attitude, brand attitude, and purchase decisions. The study provided mixed support of the selectivity hypothesis for men: Like females, males responded equally positive to both the factual and the evaluative claims, and thus did not favor the factual claims as was predicted. The authors reason this could be due to the fact that both the factual and the evaluative claims contained equally salient cues which the males used as heuristics.

However, and importantly, in Darley and Smith's (1995) study, as in the Laroche et al. (2000) study mentioned above, the possible influence of the subject of the product or message, which in turn affects evaluation and consumer purchase decisions, was not taken into consideration. The ads used in Darley and Smith's (1995) study were about 'female' products such as weighing scales and electric blankets, possibly causing men to feel less interested - which in turn may have led them to process the information less comprehensively. Similarly, the results from the Laroche et al. (2000) study show that "Shopping is still an activity in which the female plays a dominant role" (p. 504), suggesting that men might use heuristic cues when shopping for a gift because they are not interested in shopping itself. Thus, it may be that the reported differences can be at least in part attributed to gender differences in interests rather than to gender differences in information processing. Interest is commonly referred to as involvement in the consumer psychology literature, and in the remainder of the paper we shall also use involvement when referring to product interest. To be specific, following Day (1970), involvement is defined as "the general level of interest in the object, or the centrality of the object to the person's ego-structure" (p. 45).

Indeed, research has shown (e.g. Petty \& Cacioppo, 1979) that with increasing personal involvement, the likelihood that advertisements will be processed comprehensively also increases, whereas low involvement leads to heuristic processing. Based on the literature above, we therefore suggest that when involvement with a product or subject is low, people tend to process the information less comprehensively, and will be more likely to rely on evaluative arguments, since these contain an assessment of the qualities of the product and enable heuristic processing. Conversely, when one is highly involved with a product, advertisements should be processed more comprehensively, and factual arguments will be relied on for judgment. Moreover, involvement, in turn, is dependent on one's gender, and we therefore expect male subjects to be more involved with a male product (i.e. a product aimed specifically at men), whereas female subjects will be most involved with a female product.

We have chosen to use adolescents as participants in the current study. Adolescents as consumers have historically never been more influential than today-they are relatively affluent since most of them have some sort of income of their own and little or no fixed costs. Moreover, research has shown that in addition to making their own consumer decisions, adolescents also have a significant influence on family purchase decisions (Wang, Holloway, Beatty, \& Hill, 2007). As stimuli material, we chose to devise magazine ads. With respect to advertising, teens, when asked to recommend the media they thought would be most effective for advertisers to reach them, ranked radio and magazines first, followed by cable television and time slots before movies in theaters. Furthermore, girls ranked magazines 
just after friends as the most important source of information on the latest trends, fashions, and lifestyle choices (Brown \& Witherspoon, 2002). In the current study, to test our hypotheses we devised ads for magazines: two ads for a male magazine (sports) and two ads for a female magazine (youth general interest, e.g. fashion, celebrity gossip, relationships; Bügel \& Buunk, 1996). For each type of magazine, one ad described the magazine in evaluative terms and one ad described the magazine in factual terms. In the study, type of magazine (hereafter referred to as subject) will be used as a within-subjects variable and message claim will be used as a between-subjects variable, resulting in each participant reading two magazine descriptions containing either factual or evaluative message claims. After reading the descriptions participants answer questions regarding their ad attitudes, product attitudes, and purchase intentions (based on Darley \& Smith, 1995).

\section{Method}

\section{Design and Participants}

Participants were 115 male and 127 female high school students from a high school in the northern part of The Netherlands (Mean age $=17.3$, SD $=.92)$. They were randomly assigned to a mixed 2 (participant gender: male/female) $\times 2$ (message claim: evaluative/factual) $\times 2$ (magazine subject: sports/youth) design, with magazine subject as a within-participants variable, and participant gender and message claim as between-participants variables. Since they were below the legal age of participating in psychological research, our participants, their parents, and the school director signed an informed consent form in which the procedure was explained, and anonymity was ensured. All materials and procedures were approved by an Ethics Committee of Psychology.

\section{Procedure \& Materials}

The participants completed the questionnaire at their separate desks during a regular social studies class. The study was introduced as a survey on opinions about new magazines. The participants read two ads: one for a sports magazine and one for a youth magazine. The order was reversed for half of the participants. Both ads were either written in evaluative terms or in factual terms. After reading each ad, participants answered a number of questions to measure advertising response (based on Darley \& Smith, 1995). Thus, they responded to the following dependent variables twice:

Ad attitude was measured by asking participants to indicate on a 7-point scale ([1] = absolutely not, [7] = absolutely) how good, interesting, pleasant, amusing, and fascinating they thought the ad was. Coefficient alpha for these 5 items was .89 for the sport magazine ad and .90 for the youth magazine ad. It was therefore decided to average these items into the single variable Ad Attitude; $\mathrm{M}_{\text {sports }}=3.79(\mathrm{SD}=1.16), \mathrm{M}_{\text {youth }}=3.81$ $(\mathrm{SD}=1.19)$.

Product attitude was measured by asking participants to indicate on a 7-point scale ([1] = absolutely not, [7] = absolutely) how good, interesting, pleasant, amusing, and fascinating they thought the magazine they had read about was. Coefficient alpha for these items was .94 for the sport magazine ad and .95 for the youth magazine ad. It was therefore decided to average these items into the single variable Product Attitude; $\mathrm{M}_{\text {sports }}=$ $4.10(\mathrm{SD}=1.29), \mathrm{M}_{\text {youth }}=4.10(\mathrm{SD}=1.30)$.
To measure purchase intention, the participants indicated on a 7-point scale ([1] = definitely not, [7] = definitely) the probability of buying the magazine when it became available, and the likelihood that they would recommend the magazine to a friend. These items were highly correlated $(r=.65$ for the sport magazine ad, and $\mathrm{r}=.79$ for the youth magazine ad) and it was decided to combine them into a single variable, Purchase Intention. $\mathrm{M}_{\text {sports }}=3.15(\mathrm{SD}=1.59), \mathrm{M}_{\text {youth }}=3.38(\mathrm{SD}=1.77)$.

Finally, as a manipulation check, participants indicated on a 7-point scale ([1] = absolutely not, [7] = absolutely) how factual and how evaluative they thought the ads were. These terms were briefly explained to the participants in the questionnaire booklet, by stating how an evaluative ad contains (value) judgments about a product's qualities, whereas a factual ad only contains factual information but does not provide interpretations or value judgments about this information. After completing the questionnaire, participants were thanked for their participation and thoroughly debriefed.

\section{Results}

The hypotheses were tested in several repeated measures ANOVAs with gender (male/female), message claim (evaluative/factual) and subject (within participants: sports/youth) as the independent variables, and the manipulation check items, ad attitude, product attitude, and purchase intention as the dependent variables. For an overview of all means and SD's, see Table 1.

First, we performed manipulation checks. The analysis for the item "evaluative" showed a significant main effect of message claim: $F(1,235)=70.29, \eta^{2}=.23, p<.001$. As expected,

Table 1.

Mean scores (and SD's) on Ad Attitude, Product Attitude, and Purchase Intention for a factual or evaluative sports or youth magazine ad, as judged by males $(\mathrm{N}=115)$ and females $(\mathrm{N}=127)$.

\begin{tabular}{|c|c|c|c|}
\hline Subject & Gender & Factual Ad & Evaluative Ad \\
\hline & & \multicolumn{2}{|c|}{ Ad Attitude } \\
\hline \multirow{2}{*}{ Youth } & Male & $3.43(1.14)$ & $3.60(1.08)$ \\
\hline & Female & $4.40(1.16)$ & $3.72(1.18)$ \\
\hline \multirow{2}{*}{ Sports } & Male & $3.87(1.34)$ & $3.85(1.12)$ \\
\hline & Female & $3.50(1.07)$ & $3.96(.29)$ \\
\hline & & \multicolumn{2}{|c|}{ Product Attitude } \\
\hline \multirow{2}{*}{ Youth } & Male & $3.71(1.34)$ & 3.77 (1.29) \\
\hline & Female & $4.73(1.06)$ & $4.06(1.28)$ \\
\hline \multirow{2}{*}{ Sports } & Male & $4.36(1.28)$ & $4.12(1.37)$ \\
\hline & Female & $3.76(1.17)$ & $3.76(1.25)$ \\
\hline & & \multicolumn{2}{|c|}{ Purchase Intention } \\
\hline \multirow{2}{*}{ Youth } & Male & $2.83(1.66)$ & $2.54(1.60)$ \\
\hline & Female & $4.51(1.45)$ & $3.51(1.69)$ \\
\hline \multirow{2}{*}{ Sports } & Male & $3.41(1.73)$ & 3.09 (1.64) \\
\hline & Female & $2.84(1.34)$ & $3.31(1.64)$ \\
\hline
\end{tabular}


participants judged the evaluative ads as more evaluative $(\mathrm{M}=$ 4.63) than the factual ads $(M=3.17)$. Analysis for the item "factual" also revealed a main effect of message claim: $F(1,135)$ $=103.17, \eta^{2}=.30, p<.001$ Participants judged the factual ads as more factual $(\mathrm{M}=5.42)$ than the evaluative ads $(\mathrm{M}=3.65)$. Based on these results, it is concluded that the ads were judged as they were intended, and that further analyses were justified.

The ANOVA on ad attitude yielded no significant main effects $(F$ 's $<2.84, n s)$, nor a significant two-way interaction between message claim and gender $(F(1,236)=.56, n s)$. However, the two-way interaction between magazine subject and gender was significant $\left(F(1,236)=16.95, \eta^{2}=.07, p<.001\right)$, as was the two-way interaction between subject and message claim: $F(1,236)=7.83, \eta^{2}=.03, p<.01$. Participants had a more positive attitude toward the evaluative than to the factual sports magazine ad, and a more positive attitude toward the factual than to the evaluative youth magazine ad. Finally, as predicted, the three-way interaction between gender, subject and message claim was highly significant: $F(1,236)=15.38, \eta^{2}$ $=.06, p<.001$ (for means, see Table 1). This interaction showed that Hypothesis 2 and 3 were confirmed for females: they had a more positive attitude towards the factual ad than towards the evaluative ad for the youth magazine $(F(1,125)$ $\left.20.31, \eta^{2}=.14, p<.001\right)$, i.e. towards an ad about a high involvement product. However, towards the sports magazine, they reported a more positive attitude towards the evaluative ad than towards the factual ad. Males did not differ in their attitudes toward evaluative and factual ads for either magazine $(F(1,113)=.98, n s)$, so for males the hypotheses could not be confirmed.

Similar results were found for product attitude: no significant main effects ( $F$ 's $<2.86, n s)$, and no significant two-way interaction between message claim and gender $(F(1,237)$ $=.002, n s)$. The two-way interaction between subject and gender was significant: $F(1,237)=20.71, \eta^{2}=.08, p<.001$, as was the two-way interaction between subject and message claim: $F(1,237)=4.68, \eta^{2}=.02, p<.05$. Both male and female participants had a more positive attitude toward the sports magazine when the ad was evaluative rather than factual, whereas they had a more positive attitude toward the youth magazine when the ad was factual rather than evaluative. Finally, the three-way interaction between gender, subject and description was significant: $F(1,237)=12.95, \eta^{2}=.05, p$ $<.001$, revealing that again, Hypotheses 2 and 3 could be confirmed for female participants. Females had a more positive attitude toward the youth magazine - a high involvement product for them-when the ad was factual rather than evaluative, but had a more positive attitude toward the sports magazine- - a low involvement product-when the ad was evaluative rather than factual $\left(F(1,125)=16.21, \eta^{2}=.12, p<.001\right)$. For males, this interaction was not significant $(F(1,112)=1.08, n s)$, and the hypotheses could not be confirmed.

A purchase intention ANOVA yielded a significant main effect for gender $\left(F(1,237)=13.35, \eta^{2}=.05, p<.001\right)$ : female participants had a greater intention to buy magazines than male participants. No other main effects were significant ( $F$ 's $<3.31$, $n s)$. There were significant two-way interactions between gender and subject $\left(F(1,237)=31.16, \eta^{2}=.12, p<.001\right)$, and between subject and message claim: $F(1,237)=6.99, \eta^{2}=.03$, $p<.01$. Participants had a larger intention to buy the youth magazine when the ad was factual rather than evaluative, whereas the reverse was true for the sports magazine. The two-way interaction between gender and description was not significant $(F(1,237)=.02, n s)$. Again, there was a significant three-way interaction: $F(1,237)=8.51, \eta^{2}=.04, p<.01$. Female participants reported a higher purchase intention for the youth magazine when the ad was factual rather than evaluative $\left(F(1,125)=14.51, \eta^{2}=.10, p<.001\right)$, whereas they indicated a higher purchase intention for the sports magazine when the message claims in the ad were evaluative as opposed to factual. Again, for male participants, this interaction was not significant $(F(1,112)=.04, n s)$, and only magazine subject influenced their purchase intentions. Male participants were more likely to buy a sports magazine than a youth magazine.

\section{Discussion}

Research based on the selectivity hypothesis has previously reported gender differences in the information processing of ads (e.g., Meyers-Levy, 1989; Darley \& Smith, 1995), and authors have suggested these differences could be attributed to females' more comprehensive information processing and males' tendency to rely on salient cues and heuristics. The current study has attempted to add to this literature by investigating whether the type of product — or more specifically, participants' level of involvement with a certain product-also influences ad and product judgments and purchase intentions.

The current results support our hypotheses: in addition to message claims, we found that indeed, product involvement plays a role in determining advertising response among males and females. In other words, we suggest that the subject of the message largely influences which information will be processed. More specifically, we found that when the ad contained a description of a high involvement product, females were persuaded most by factual information, whereas when the ad contained a description of a low involvement product, they were more likely to be persuaded by evaluative information. This result fits in with research by Brunel and Nelson (2000, 2003), who reported that when participants were told that they were participating in a copy-testing study for a real international aid agency, and that their responses would be essential to the research-i.e., when high involvement was induced-ads were scrutinized on their content and assessed for a fit with one's attitudes and values. Their results showed that both males and females rated ads that were congruent with their world-view values more positively than ads that were incongruent with their values.

However, and contrary to our expectations, in the current study males were not to such an extent as females influenced by the way in which low and high involvement products were described, i.e. by the type of message claim. Although males overall did indicate a more positive attitude toward the "male" subject - the sports magazine - the results suggest that this judgment was not influenced by the description of the advertisements: males were persuaded by both evaluative and factual message claims. This finding however is consistent with results from other investigations into gender differences in information processing. For example, Darley \& Smith (1995) also found that males showed consistent response patterns over the two levels of product risk that were induced. These authors showed no significant differences in responses to objective (factual) and subjective (evaluative) claims for four out of five measures, although also no product preference emerged, which could be due to the use of primarily female products (electric blanket and 
weighing scale).

Apparently, then, men's purchase intention depends more on the product (high or low involvement) than on the way this product is described in the advertisements. This has also been found by Alreck, Settle, and Belch (1982), who showed that generally, men preferred masculine soap brands and did not readily accept female soap brands, especially when they held strong attitudes about gender roles. However, an alternative explanation for this finding might be that, even though we have taken care to choose subjects for the magazines that would appeal both to females and males, females generally are more interested in magazines than males. Indeed, as the results indicated, females did report a greater overall purchase intention, and previous research has also shown that females consider magazines more often as sources of information than males do (Brown \&Witherspoon, 2002). Thus, in this sense, the involvement of our male participants could have been lower than we intended, which in turn could have caused them to consider merely the product rather than the message claims. Moreover, the result also fits in with research by Mitchell and Walsh (2004) who found that men's consumer behavior is characterized by a time-saving orientation. Perhaps males are focused only on finding a product they prefer, focusing only on this factor, and, as it were, ignoring the way the product is described or sold to them. This issue should be investigated in future research.

Based on these results, we suggest that it is not gender per se that influences information processing style, but one's level of product involvement, and the way the product is presented, i.e. the message claims that are made in the ad. This conclusion has consequences for the marketing practice. Marketers should not only take the "gender" of the product they are selling into consideration, but also how they would advertise this product to males or females (see also Buunk \& Dijkstra, 2011). As the current study suggests, a male product advertised to a female audience requires a different description than a female product for the same audience. For the male target group it seems not to matter in which way the product is described: males in general seem to favor a male product rather than a female product, independent of the description.

\section{Limitations and Future Research}

As with any empirical study, the current one has several limitations that need to be addressed. Since this study was conducted among high school students, the current study may not be representative of the broad range of today's consumers. Variables like social class and income may have an impact on ad evaluation and preferences. It is therefore important that this study is replicated with "real" consumers, and preferably with consumers from different ethnicities and cultures. Moreover, the current study focuses only on written ads. Nowadays, consumers are confronted with a vast amount of persuasive messages, on the radio, in newspapers and magazines, on the television, and, not unimportantly, on the internet. Future studies should investigate the combined effects of message claims, gender and the subject of the advertisements to determine whether it is possible to generalize the results reported here to different media. Finally, the choice of product-magazinescould have influenced the results as women are in general more interested in reading magazines than men, causing them to be more involved with the ads.
The results from the current study provide several implications for future research. In the current study a male and a female topic were compared, and the results suggest that this comparison is a useful theoretical method to test the influence of the subject on the way of information processing. However, although the results clearly indicate that women were more interested in the youth magazine and men in the sports magazine, this assumption was not explicitly tested. In future research, it is important to explicitly ask participants about their interests and preferably tailor the ads to these, in addition to controlling for their level of interest in the issue at hand: do the reported differences disappear when controlling for interest? Moreover, research using gender neutral topics would be an addition to the insights of this study. If females and males do not use different information processing strategies, or focus on different types of message claims when evaluating an ad for a gender neutral subject, this would strengthen the assumption that one's involvement with the product described in the message is responsible for the way of information processing, and not gender. One of the central hypotheses of the current study was that males and females respond differently to evaluative and factual information under the influence of their involvement with the product advertised. One further test of this hypothesis is to design advertisements - for male, female, and neutral subjects - that contain both evaluative and factual arguments. Message recall could then be a way to determine which type of claims appeal most to which gender, and for which subject. And, finally, future research should focus on the information processing strategies of males: which factors determine the finding that females do make a difference between message claims about products within and outside their area of interests and males do not?

\section{Conclusion}

To conclude, the current study shows that when an ad contained a description of a high involvement product, females were persuaded most by factual information, whereas when the ad contained a description of a low involvement product, they were more likely to be persuaded by evaluative information. For males, the results were less clear. Although males overall did indicate a more positive attitude toward the male subject, they were persuaded equally by evaluative and factual information. The current study clearly shows that gendered advertising responses exist, and that they interact with message claims, and that marketers would benefit from designing ads for females differently than ads for men.

\section{REFERENCES}

Alexander, G. M., Wilcox, T., \& Woods, R. (2009). Sex differences in infants' visual interest in toys. Archives of Sexual Behavior, 38, 427-433. doi:10.1007/s10508-008-9430-1

Alreck, P. L., Settle, R. B., \& Belch, M. A. (1982). Who responds to "gendered" ads, and how? Masculine brands versus feminine brands. Journal of Advertising Research, 22, 25-32.

Brown, J. D., \& Witherspoon, E. M. (2002). The mass media and American adolescents' health. Journal of Adolescent Health, 31, 153-170. doi:10.1016/S1054-139X(02)00507-4

Brunel, F. F., \& Nelson, M. R. (2000). Explaining gendered responses to "help-self" and "help-others" charity adappeals: The mediating role of world-views. Journal of Advertising, 29, 15-28. doi:10.1080/00913367.2000.10673614 
Brunel, F. F., \& Nelson, M. R. (2003). Message order effects and gender differences in advertising persuasion. Journal of Advertising Research, 43, 330-341. doi:10.1017/S0021849903030320

Bügel, K., \& Buunk, B. P. (1996). Sex differences in foreign language text comprehension: The role of interests and prior knowledge. The Modern Language Journal, 80, 15-31.

Buunk, A. P., \& Dijkstra, P. (2011). Does attractiveness sell? Women's attitude towards a product as a function of model attractiveness, gender priming and social comparison orientation. Psychology and Marketing, 28, 958-973. doi:10.1002/mar.20421

Darley, W., \& Smith, R. (1993). Advertising claim objectivity: Antecedents and effects. Journal of Marketing, 57, 100-113. doi:10.2307/1252222

Darley, W., \& Smith, R. (1995). Gender differences in information processing strategies: An empirical test of the selectivity model in advertising responses. Journal of Advertising, 24, 41-56. doi:10.1080/00913367.1995.10673467

Day, G. S. (1970). Buyer attitudes and brand choice. New York: Free Press.

Eccles, J., Wigfield, A., Harold, R. D., \& Blumenfeld, P. (1993). Age and gender differences in children's self- and task perceptions during elementary school. Child Development, 64, 830-847.

Edell, J. A., \& Staelin, R. (1983). The information processing of pictures in print advertisements. The Journal of Consumer Research, 10, 45-61. doi: $10.2307 / 1131221$

Holbrook, M. B. (1978). Beyond attitude structure: Toward the informational determinants of attitude. Journal of Marketing Research, 15, 545-556. doi: $10.2307 / 3150624$

Kottler, P., \& Keller, K. L. (2006). Marketing management (12th ed.). Upper Saddle River, NJ: Prentice Hall.

Laroche, M., Saad, G., Cleveland, M., \& Browne, E. (2000). Gender differences in information search strategies for a Christmas gift. Journal of Consumer Marketing, 17, 500-524. doi:10.1108/07363760010349920

Lippa, R. A. (2010). Gender differences in personality and interests: When, where, and why? Social and Personality Psychology Compass, 4, 1098-1110. doi:10.1111/j.1751-9004.2010.00320.x

Meyers-Levy, J. (1989), Gender differences in information processing: A selectivity interpretation. In P. Cafferata, \& A. M. Tybout (Eds.),
Cognitive and affective responses to advertising. Lexington, MA: Lexington Books/DC Heath \& Com.

Meyers-Levy, J., \& Maheswaran, D., (1991). Exploring differences in males' and females' processing strategies. Journal of Consumer Research, 18, 63-70. doi:10.1086/209241

Meyers-Levy, J., \& Sternthal, B. (1991). Gender differences in the use of message cues and judgments. Journal of Marketing Research, 28, 84-96. doi: $10.2307 / 3172728$

Mitchell, V. W., \& Walsh, G. (2004). Gender differences in German consumer decision-making styles. Journal of Consumer Behaviour, 3, 331-346. doi: $10.1002 / \mathrm{cb} .146$

Nysveen, H., Pedersen, P. E., \& Thorbjørnsen, H. (2005). Explaining intention to use mobile chat services: Moderating effects of gender. Journal of Consumer Marketing, 22, 247-256. doi: $10.1108 / 07363760510611671$

Petty, R., \& Cacioppo, J. (1979). Issue involvement can increase or decrease persuasion by enhancing message-relevant cognitive responses. Journal of Personality and Social Psychology, 37, 19151926. doi:10.1037/0022-3514.37.10.1915

Slama, M. E., \& Williams, T. G. (1990). Generalization of the market maven's information provision tendency across product categories. In: M. E. Goldberg, G. Gorn, \& R. W. Pollay (Eds.), Advances in consumer research (Vol. 17, pp. 48-52). Provo, UT: Association for Consumer Research.

Tan, S. J. (2002). Can consumers' skepticism be mitigated by claim objectivity and claim extremity? Journal of Marketing Communications, 8, 45-64. doi:10.1080/13527260210122097

Trainor, S., Delfabbro, P., Anderson, S., \& Winefield, A. (2010). Leisure activities and adolescent psychological well-being. Journal of Adolescence, 33, 173-186. doi:10.1016/j.adolescence.2009.03.013

Wang, S., Holloway, B. B., Beatty, S. E., \& Hill, W. W. (2007). Adolescent influence in family purchase decisions: An update and crossnational extension. Journal of Business Research, 60, 1117-1124. doi:10.1016/j.jbusres.2007.04.004

Wolin, L. D. (2003). Gender issues in advertising-An over sight. Synthesis of research: 1970-2002. Journal of Advertising Research, 43, 111-129. 